Archives de sciences sociales des religions

136 | octobre - décembre 2006

Les Archives... cinquante ans après

\title{
Ruminations d'un dinosaure
}

Jacques Maître

\section{(2) OpenEdition}

\section{Journals}

Édition électronique

URL : http://journals.openedition.org/assr/3816

DOI : $10.4000 /$ assr.3816

ISSN : $1777-5825$

Éditeur

Éditions de l'EHESS

Édition imprimée

Date de publication : 1 décembre 2006

Pagination : 63-65

ISBN : 2-7132-2124-2

ISSN : 0335-5985

Référence électronique

Jacques Maître, "Ruminations d'un dinosaure », Archives de sciences sociales des religions [En ligne], 136 | octobre - décembre 2006, mis en ligne le 02 janvier 2009, consulté le 01 mai 2019. URL : http:// journals.openedition.org/assr/3816 ; DOI : 10.4000/assr.3816 


\section{Jacques Maître}

\section{Ruminations d'un dinosaure}

Dans le champ des sciences humaines, on dit parfois qu'une revue est l'œuvre d'une génération. J'ai entendu des collègues nous le rappeler au cours des premières années des ASSR. Assez âgé pour en avoir été un des fondateurs au milieu du siècle dernier, j'éprouve un plaisir intense à constater que les générations montantes ont su tirer parti de cet outil de travail tout en construisant des problématiques très nouvelles.

L'année dernière, les organisateurs d'un colloque sur « Le sacré hors religion » (colloque de l'AFSR, Paris, février 2005) m'avaient demandé d'analyser rétrospectivement ma trajectoire personnelle de chercheur; ma communication s'est intitulée "Au fil des décennies, l'objet, la problématique et le chercheur ne cessent pas de muter ». Je me trouve ainsi dispensé de raconter à nouveau ma vie (professionnelle, s'entend). C'est donc uniquement sur la revue que je vais livrer quelques réflexions personnelles.

La contribution d'Émile Poulat au présent numéro retrace avec beaucoup de rigueur chronologique et conceptuelle les « origines du Groupe de sociologie des religions et de ses Archives". Il accomplit ce retour sur l'histoire des ASSR en relatant minutieusement le déroulement des nombreuses années qui ont suivi cette période originelle jusqu'au moment où les fondateurs survivants - les archevêques, disait-on cum grano salis - ont quitté d'un commun accord le comité de rédaction pour laisser les mains libres à la génération suivante. De mon côté, je me propose seulement de réfléchir sur les interactions épistémologiques entre des changements surprenants dans le champ religieux et des innovations stimulantes dans la construction d'objets, en me bornant à ce qui concerne les Français de tradition catholique.

\section{Les typologies des appartenances religieuses}

Lors du lancement de la revue, au milieu du dernier siècle du deuxième millénaire, la volonté d'affranchir la recherche sur le champ religieux par rapport à toute allégeance confessionnelle ou anti-confessionnelle constitue un moment dans la décentration de la science par rapport à l'idéologie. Déjà, l'explication 
scientifique du monde avait conquis de vastes territoires anciennement contrôlés par les autorités ecclésiastiques ; la révolution copernicienne et le procès de Galilée restent emblématiques de ce combat. Vint ensuite le moment où on vit déferler les explications non religieuses des faits religieux eux-mêmes. Au milieu du $\mathrm{XX}^{\mathrm{e}}$ siècle, l'apparition des $A S R$ déclenchera des pressions ecclésiastiques sur G. Le Bras pour qu'il noie cet enfant bâtard dont la vocation va être de promouvoir une sociologie des religions, au lieu d'une sociologie religieuse inféodée à la hiérarchie catholique. Plus grave encore, avec les $A S R$, il ne s'agira pas d'une entreprise polémique où la question centrale resterait l'engagement d'un auteur pour ou contre l'Église, comme la plupart du temps sous la Troisième République dans la production universitaire. Déjà, l'histoire des religions et l'ethnographie religieuse avaient largement ouvert la voie d'une liberté de pensée nouvelle à ce sujet, notamment à travers le comparatisme. Mais la nouvelle revue se donnera pour objet d'étudier sereinement les questions brûlantes qui commencent à déconcerter la « pastorale », en particulier autour de l' « irréligion » massive de la classe ouvrière et à propos des régions échappant à l'emprise ecclésiastique. Alors que l'épiscopat se proposait de lever les obstacles empêchant que les Français d'ascendance catholique aillent à la messe, des chercheurs vont se demander ce qui peut pousser une fraction de la population vers les pratiques cultuelles prescrites, alors que les croyances obligatoires se trouvent largement ébranlées dans l'opinion publique.

Le développement des enquêtes et relevés statistiques montrait des corrélations très fortes entre les croyances, pratiques ou valeurs et les "variables situationnelles » : âge, sexe, profession, taille de l'agglomération. Mesurées à l'aune de la distance sociale à l'Église, les références canoniques permettent encore aujourd'hui de mesurer les corrélations de cette distance avec des données idéologiques : attitudes politiques, éthique sexuelle, compétition entre science et parasciences. En même temps, les enquêtes mettent en évidence la disjonction croissante entre les attitudes courantes, même chez les catholiques pratiquants, et les injonctions du Magistère, dès que nous sortons du consensus général (droits de l'Homme, etc.) pour aller vers les positions spécifiques de l'Église, en particulier lorsqu'il s'agit de la sexualité ou de la mort volontaire.

Le pire restait à venir. Impavides et neutres devant les autorités confessionnelles, nous ne savions pas encore à quel point nos conceptualisations restaient ecclésio-centriques. Par exemple, nous avions bien repéré que les questionnaires des sondages sur les attitudes religieuses étaient surtout des examens de catéchisation, car construits par des commanditaires soucieux avant tout de mesurer l'emprise de l'Église sur la société. Mais il aura fallu des années de maturation et des outillages méthodologiques appropriés pour sortir de ce piège, par exemple avec les entretiens non directifs et les analyses de contenu, c'est-à-dire des démarches plus qualitatives.

Au cours des années 1950 et 1960, la religion est pratiquement définie par la référence à l'institution confessionnelle. L'emprise du catholicisme sur la 
population reste considérée comme peu sujette à des variations rapides. Les sondages sont commandités par des périodiques catholiques ou bien-pensants, avec des questions centrées sur les croyances inculquées au catéchisme à une écrasante majorité de la population et sur les comportements cultuels publics canoniquement obligatoires; nous sommes très près de la thématique du liber status animarum des époques où le catholicisme était la religion officielle. Les populations religieuses se trouvent catégorisées en cercles concentriques dont le rayon traduit une distance par rapport à l'Église. Le fait que nous assistions au commencement de la fin d'un monde est masqué par une problématique de recherche calée sur les clivages sociaux (classes, sexes, âges, régions...) plus que sur les changements. Les évolutions repérées jouent sur le long terme (par exemple à propos des délais de baptême). Les élaborations théoriques se fondent sur des classiques qui ont mis l'accent sur des mutations séculaires caractéristiques d'une sorte de modernité devenue lentement classique.

\section{Et maintenant}

Dans la France d'aujourd'hui, par rapport au total annuel des naissances, le taux des baptêmes et celui des enfants nés hors mariage sont en train de se croiser dans l'escalier, franchissant en sens inverses la barre des $50 \%$. Les effectifs du clergé fondent à vue d'œil. La proportion des jeunes catéchisés devient très minoritaire, tandis que les médias plongent les nouvelles générations dans un flot d'informations disparates sur les faits religieux. Depuis les héritages ancestraux d'aires culturelles exotiques jusqu'aux mythologies créées par les auteurs de science-fiction et de bandes dessinées, depuis les hyperorthodoxies jusqu'aux interprétations les plus hétérodoxes de l'histoire du christianisme, une avalanche de fascinations religieuses submerge la jeunesse. En même temps, une chaîne comme Arte présente des documentaires et des débats scientifiques mettant en question les dogmes non par des attaques polémiques, mais par la relativisation inhérente à un traitement intellectuellement égalitaire des traditions religieuses les plus diverses.

Même s'agissant des héritages monothéistes, les ASSR donnent une large place aux effervescences actuelles, souvent sur la base d'enquêtes menées à chaud, alors que nous avions privilégié des turbulences anciennes bien refroidies. H. Desroche avait, de longue date, pointé cette orientation en soulignant avec humour que nous n'avions pas pour rien intitulé la revue "archives".

Les changements que la sociologie actuelle pointe comme " recompositions du champ religieux " rendent progressivement obsolète tout un pan des nos constructions d'objet. Les paradigmes centrés sur les confessions religieuses ont cédé la place à des références beaucoup plus mobiles et novatrices. Mutations de l'objet et innovations des problématiques poursuivent leur compétition. Quel bonheur pour les vieux de la vieille, témoins que la relève se trouve amplement assurée sur le terrain de la créativité scientifique! Cette jouissance-là vaut promesse de vie éternelle pour notre postérité, sinon pour les ASSR elles-mêmes... 
